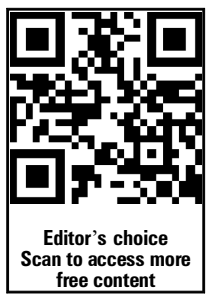

Scottish Senior Clinical Fellow and Consultant in Reproductive Medicine, MRC Centre for Reproductive Health, The University of Edinburgh, Edinburgh, UK

\section{Correspondence to} Dr W Colin Duncan, MRC Centre for Reproductive Health, The Queen's Medical Research Institute, The University of Edinburgh, 47 Little France Crescent, Edinburgh EH16 4TJ, UK:

W.C.Duncan@ed.ac.uk

Received 18 June 2013 Revised 10 January 2014 Accepted 6 February 2014 Published Online First

3 March 2014
CrossMark

To cite: Duncan WC. J Fam Plann Reprod Health Care 2014;40:217-225.

\title{
A guide to understanding polycystic ovary syndrome (PCOS)
}

\author{
W Colin Duncan
}

\begin{abstract}
Polycystic ovary syndrome (PCOS) is the commonest endocrine disorder affecting women of reproductive age. Some $20 \%$ of women will have polycystic ovaries on an ultrasound scan and around $7 \%$ of women have the additional clinical or biochemical features of PCOS. As a complex multisystem disorder its background can be confusing to understand. They key feature, however, is an increased production of androgen by the ovaries. This review uses ovarian biology to describe a strategy to aid understanding and explanation of PCOS. This framework can be also be used to teach about PCOS and to inform different approaches to its management.
\end{abstract}

\section{INTRODUCTION}

Polycystic ovary syndrome (PCOS) is the commonest endocrine disorder to affect women in their reproductive years. Around $20 \%$ of women have the characteristic appearance of polycystic ovaries on ultrasound scans ${ }^{1}$ and $7-8 \%$ have the additional clinical and biochemical features of PCOS itself. ${ }^{2}$ As obesity increases the proportion of women with polycystic ovaries who develop the syndrome, the current epidemic of obesity is likely to make PCOS even more common. ${ }^{3}$

Polycystic ovaries found on ultrasound scanning will often have no clinical effects, but PCOS is the most common diagnosis made in women presenting with amenorrhoea, oligomenorrhoea or heavy, irregular and prolonged periods. It is the commonest cause of hirsutism and of infertility due to anovulation. Women with PCOS have increased concentrations of circulating androgens and there is a marked association with insulin resistance, dyslipidaemia, obesity, gestational diabetes, type 2 diabetes and heart disease. In addition, it is an established cause of endometrial hyperplasia and it is therefore linked to endometrial cancer. The short- and long-term consequences

\section{Key message points}

- Polycystic ovary syndrome (PCOS) is a common condition affecting $7 \%$ of women but its background can be confusing to understand.

- The key feature is increased production of androgen by the ovaries.

- Understanding ovarian biology clarifies pathways to androgen increase and provides a framework to facilitate teaching on PCOS.

- This approach can be also used to inform management strategies.

of PCOS represent an increasing burden on health resources.

In recent years there has been increasing consensus about the criteria required to establish the diagnosis of PCOS. Two out of the three features below are used when other causes of those clinical features have been excluded. ${ }^{4}$ Exclusion of these other, much rarer, causes often needs no more than a routine clinical assessment.

The three features are:

- anovulation or oligo-ovulation;

- the presence of polycystic ovaries on pelvic ultrasonography;

- clinical and/or biochemical signs of hyperandrogenism.

While awareness of PCOS, its diagnosis and associated morbidity is high, its basic pathophysiology is often poorly understood. This article presents a framework for teaching and increasing understanding about the causes and management of PCOS.

\section{AN APPROACH TO TEACHING AND LEARNING ABOUT PCOS}

Undergraduate students, nurses, specialist trainees and even trained gynaecologists 
often find PCOS difficult to understand, particularly as the clinical features vary from patient to patient. One strategy that can be used when teaching about PCOS is to go back to basic ovarian biology and to use that as a starting point. This leads to a framework that lends itself to formal presentation, but also to informal illustrations in the clinic or in a tutorial. In addition it allows the management strategies to be described and understood. While different experts may have alternative views of its pathophysiological basis, and some assumptions can be questioned, the following model gives a useful framework to build upon and to introduce key concepts and management pathways.

In this framework there are six stages of development of information on the biology of the ovary and the factors that interact with it that help to clarify the background to the development of PCOS. Knowledge of these stages is then used as the key to understanding the approaches available for its management.

\section{How follicles make estrogen}

The first stage in this approach is to look at the production of sex steroids, particularly estradiol, within the ovarian follicle (Figure 1a). The follicle has two steroidogenic cell layers: the outer theca cell layer and the inner granulosa cell layer, separated by a basement membrane $^{5}$ (Figure 1b). It is the granulosa cells that are responsible for the synthesis and secretion of estradiol. They do this initially under the stimulation of follicle-stimulating hormone (FSH) from the anterior pituitary gland, which binds to and activates their FSH receptors ${ }^{6}$ (Figure 1c).

Estradiol is a sex steroid and all steroids are derived from cholesterol. ${ }^{7}$ Cholesterol therefore has to be changed into estradiol by enzymatic modification through a series of intermediate steroids. In the pathway from cholesterol to estrogen, the step before estrogen is androgen (Figure 1d). Androgen is converted into estrogen by the action of the aromatase enzyme ${ }^{7}$ (Figure 1e). Granulosa cells contain large amounts of aromatase but they do not express the proteins and enzymes (steroidogenic acute regulatory protein, cholesterol side chain cleavage enzyme, $3 \beta$-hydroxysteroid dehydrogenase and $17 \alpha$-hydroxylase) that are required for the conversion of cholesterol into androgen, so they cannot produce androgen themselves (Figure 1f).

As they cannot synthesise the androgen substrate, in order to make estradiol the granulosa cells need to get androgen from another source. The androgen is made in the theca cells and converted into estrogen in the granulosa cells (Figure 2a). Theca cells produce androgen under the stimulation of luteinising hormone (LH) from the anterior pituitary gland, which activates their LH receptors (Figure 2b). ${ }^{8}$ Thus to facilitate follicular estradiol secretion, LH causes the production of androgen from cholesterol in theca cells, and FSH promotes the conversion of those androgens into estrogens in the granulosa cells (Figure 2c). This synergy between the theca and granulosa cells is known as the two-cell, twogonadotrophin model of estrogen synthesis ${ }^{9}$ and the hormones are physiologically balanced (Figure $2 \mathrm{~d}$ ).

\section{The effect of increased androgen on the ovary}

The second stage in describing the development of PCOS is to highlight that the development of a polycystic ovary is associated with increased exposure to androgens as these have their own effects on follicular growth and development. A polycystic ovary contains an increased number of small antral follicles which are the small fluid-filled follicles that are seen on naked-eye inspection of opened polycystic ovaries and are clearly visible on ultrasound scanning. They are
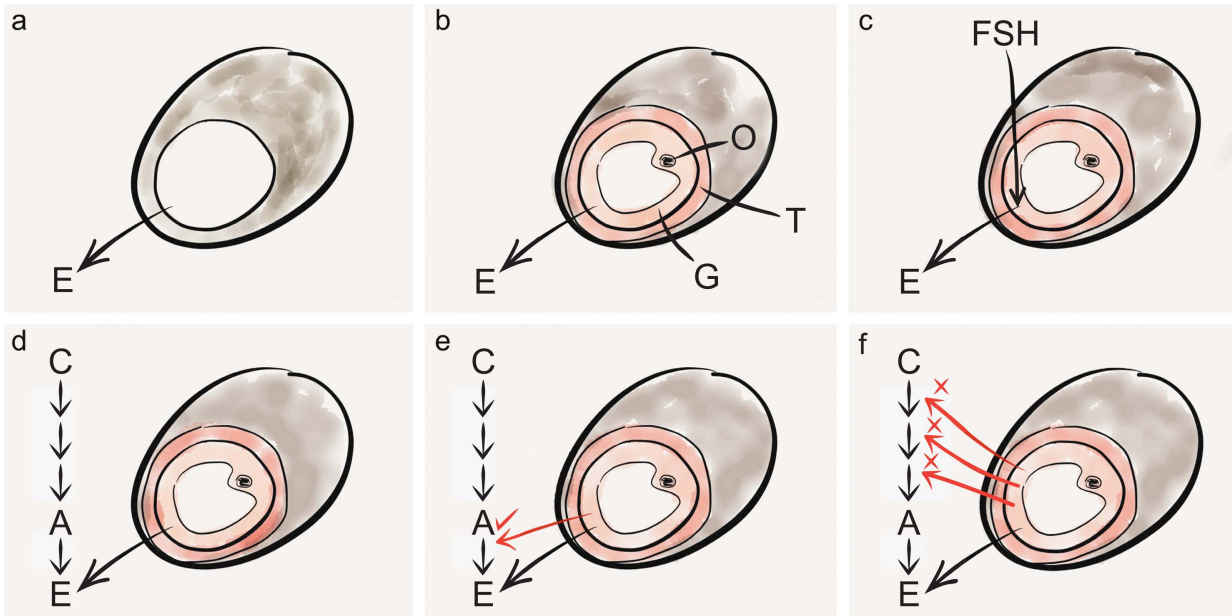

Figure 1 The pathway involved in estrogen synthesis in the ovary. Granulosa cells (G), theca cells (T) and the oocyte (O) are the key cells in the follicle. It produces estradiol (E) from cholesterol (C) after stimulation by follicle-stimulating hormone (FSH), with androgen (A) as an intermediary. See text for an explanation of stages a-f. 

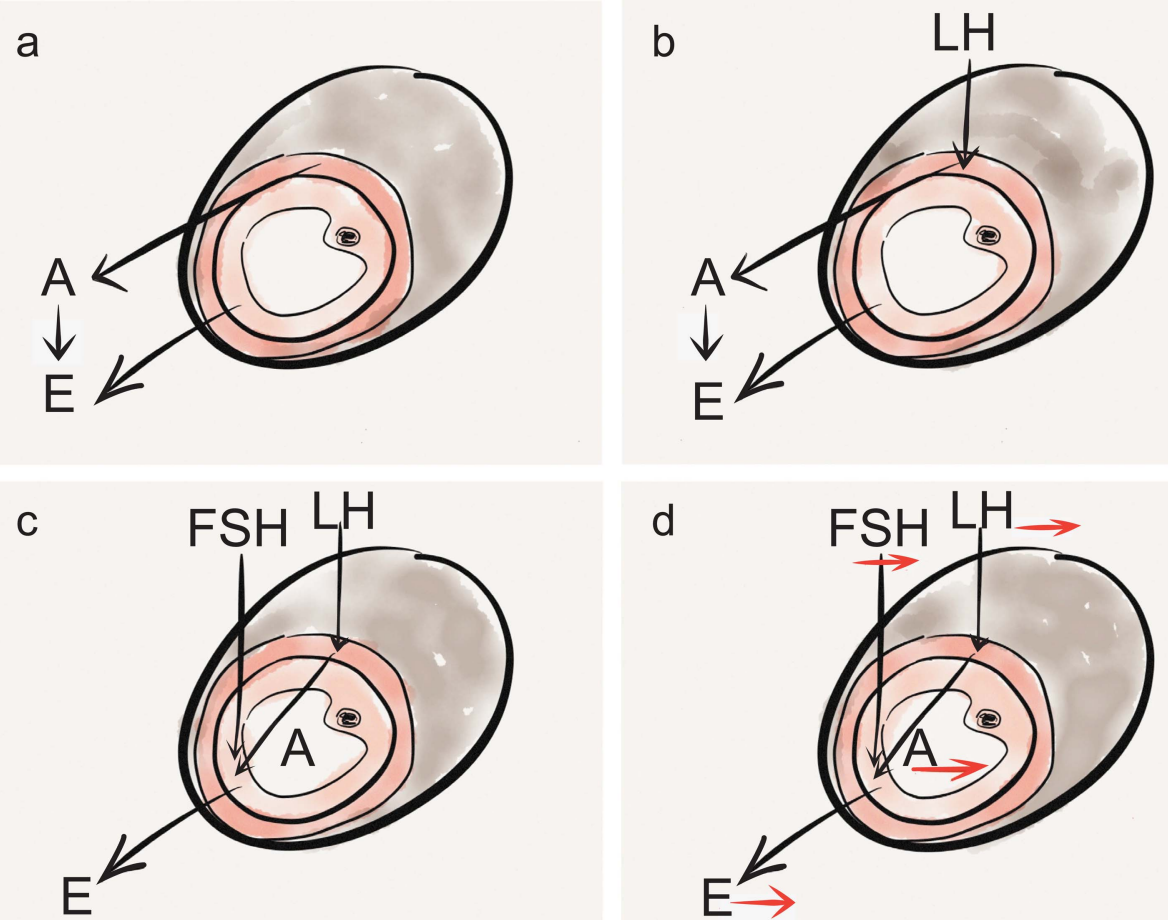

d

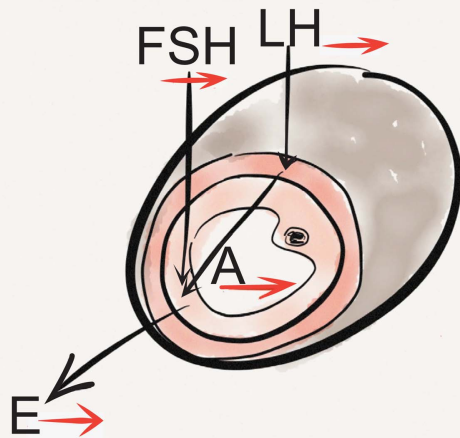

Figure 2 Illustration highlighting the two-cell two-gonadotrophin model of ovarian estradiol synthesis and its regulation. Luteinising hormone (LH) stimulates androgen (A) from theca cells which are converted to estrogen (E) in granulosa cells by follicle-stimulating hormone (FSH). See text for an explanation of stages a-d.

not 'cysts' as they contain a potentially healthy oocyte $^{10}$ and they can be stimulated to grow normally by exogenously administered FSH. ${ }^{11}$ This is why women with PCOS are at a much greater risk of developing ovarian hyperstimulation syndrome after administration of FSH during assisted conception. ${ }^{12}$ The ovarian 'cysts' in PCOS are therefore essentially paused follicles, with reduced cell growth as well as reduced cell death (atresia).

Androgen inhibits the growth of larger antral follicles but, if anything, stimulates the growth of smaller antral follicles (Figure 3a-c). Treating rhesus monkeys with normal ovaries with exogenous androgen for just 10 days resulted in a polycystic ovarian morphology, with an increased proportion of small antral follicles showing more cell proliferation in smaller follicles and less atresia in the remaining follicles. ${ }^{13}$ This highlights the ability of androgen to promote follicular growth and survival, inhibit later follicular development and directly cause a polycystic ovarian morphology.

Clinically, this polycystic ovarian morphology is associated with increased endogenous androgens. Conditions in which endogenous androgen levels are pathologically raised include androgen-secreting tumours and late-onset congenital adrenal hyperplasia, in which adrenal androgen secretion is increased. ${ }^{14}$ Women with both these conditions develop polycystic ovaries. ${ }^{15}$ The response of the ovary to increased androgens is therefore the development of a polycystic morphology and inhibition of later follicular growth. This results in an increased incidence of anovulation.

\section{Why the ovary might experience more androgen}

The third stage is to discuss the mechanisms by which the ovary might be exposed to increased local androgen concentrations. Using the two-cell, twogonadotrophin model illustrated in Figure 2d it can be demonstrated that if a hormone imbalance occurred, such that circulating LH concentrations were higher than FSH concentrations, ovarian androgen production would increase (Figure 4a). Previously an increased LH:FSH ratio was thought to be required for the diagnosis of PCOS. This is no longer part of the diagnostic criteria, which focus on the resulting increased androgens. ${ }^{4}$ However, it is clear that women with PCOS are more likely to have increased basal LH concentrations ${ }^{16}$ as well as increased LH pulse amplitude and frequency. ${ }^{17}$

While chronic anovulation can result in raised $\mathrm{LH}$ concentrations, ${ }^{18}$ it is likely that the LH:FSH imbalance is something that women with a tendency to PCOS are born with and that this causes anovulation. There is increasing evidence from human and animal models that PCOS can be programmed by increased fetal exposure to androgen before birth. ${ }^{19}{ }^{20}$ This may permanently programme increased basal LH secretion ${ }^{21}$ as well as augmenting the amount of LH released in response to gonadotrophin-releasing hormone $(\mathrm{GnRH})^{22}$ and thus the amplitude of $\mathrm{LH}$ 
a

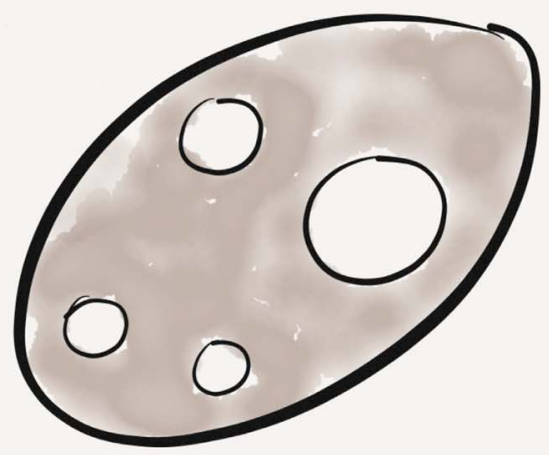

b

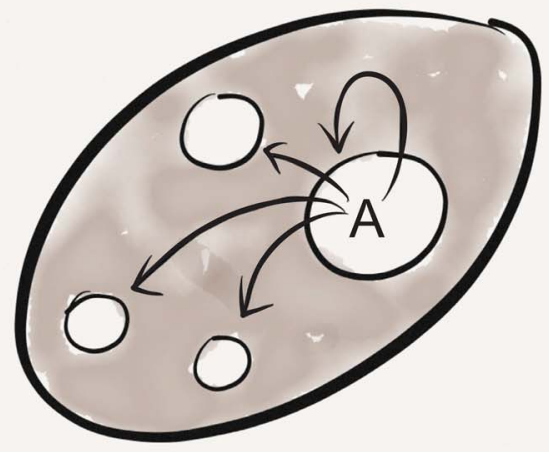

C

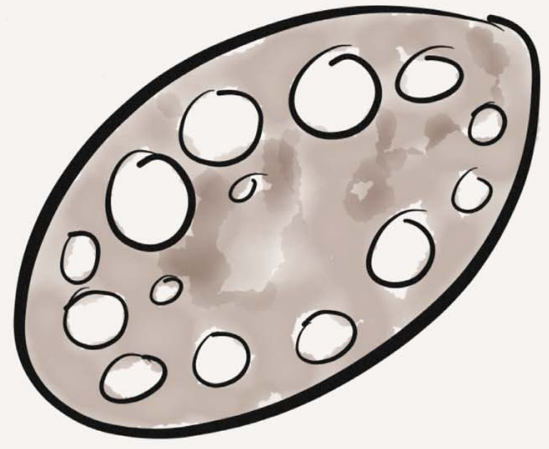

Figure 3 Diagram highlighting the role of androgens $(A)$ in the conversion of a normal ovary to one with a polycystic ovarian morphology. See text for an explanation of stages a-c.

pulses. One way the ovary can be exposed to increased androgen is therefore by an increased $\mathrm{LH}$ : FSH ratio, which may be prenatally programmed.

\section{Regulation of androgen action}

The fourth stage is to describe a regulator of androgen bioavailability. This could be imagined as a 'sponge' that can mop up excess androgen (Figure $4 b$ ) in order to prevent it affecting follicular growth and development. The sponge could normalise slightly increased ovarian androgen production (Figure 4c). However, if the sponge is small it would not fully mop up the excess androgens that are normally produced during follicular estrogen synthesis (Figure 4d). That means that there may be increased androgen bioavailability in the presence of normal LH concentrations - and if there is an increased LH:FSH ratio a small sponge would augment the increased androgen exposure (Figure 4e).

That 'sponge' exists in the form of sex hormone binding globulin (SHBG), the circulating protein that binds to and inhibits androgens and to a lesser extent estrogens (Figure 4f). For the purpose of this framework it is now useful to highlight that SHBG is inversely related to weight (Figure $4 \mathrm{~g}$ ). ${ }^{23}$ As weight increases, SHBG decreases and androgen availability will therefore increase (Figure 4h). This means that polycystic ovaries or PCOS will worsen. Conversely, as weight reduces SHBG will increase and bioavailable androgen will decrease (Figure 4i), meaning that PCOS will improve. Weight is therefore a controller of LH action on the ovary and thus the effects of LH will be exaggerated by obesity.

\section{Regulation of androgen synthesis}

The fifth stage is to focus on the molecular regulation of LH-dependent androgen synthesis by the theca cells (Figure 5a). The key here is to imagine the effect that a multiplier of LH action would have at the level of the theca cell (Figure $5 \mathrm{~b}$ ). The presence of a multiplier would augment androgen production for a given concentration of LH. That means that ovarian androgen could be increased in the presence of normal concentrations of $\mathrm{LH}$ (Figure $5 \mathrm{c}$ ).

That multiplier exists in the form of insulin (Figure 5d). This ubiquitous hormone regulates glucose transport and has growth factor and anabolic actions. $^{24}$ It is also a co-factor that augments LH-induced thecal androgen secretion. ${ }^{25}{ }^{26}$ In the presence of peripheral insulin resistance (IR), which is a precursor to impaired glucose tolerance, increased insulin concentrations are required to promote glucose uptake in tissues with a key metabolic role, such as muscle and fat. While these may be resistant to the metabolic effects of insulin, the ovary remains sensitive to its growth factor effects. The hyperinsulinaemia associated with IR therefore means that more androgen will be produced in the ovary. As IR worsens and insulin concentrations rise, ovarian androgens will increase and PCOS will worsen (Figure 5e). If IR improves and insulin concentrations fall, ovarian androgens will reduce and PCOS will improve (Figure 5f). 
a
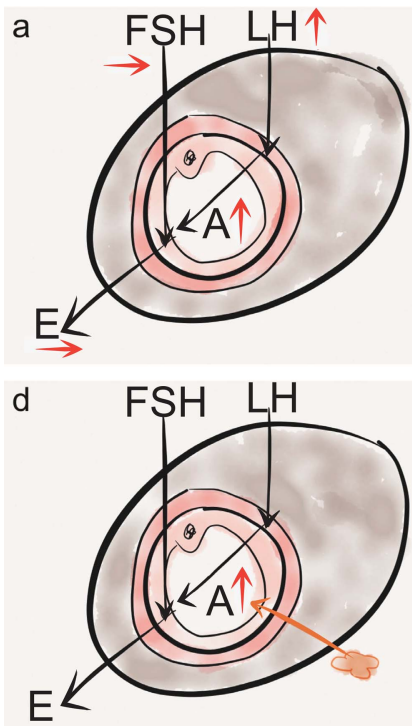

g

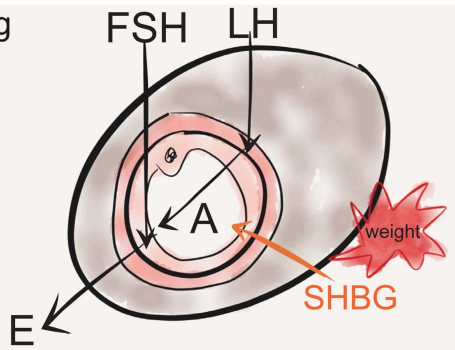

b

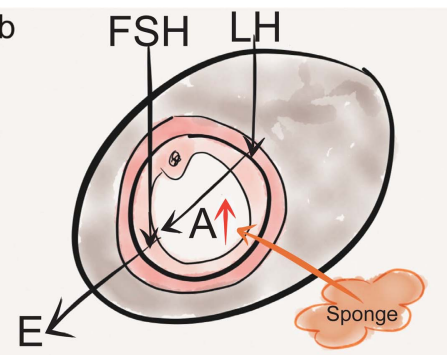

e
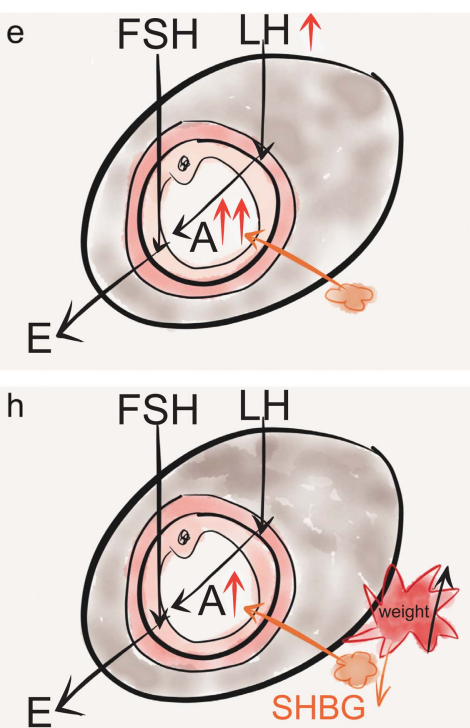

C

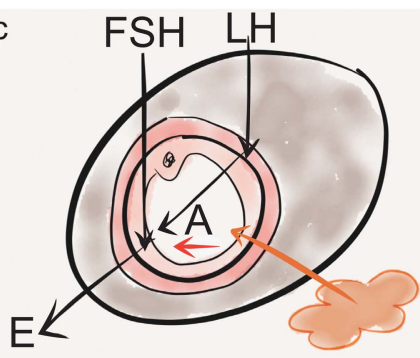

f
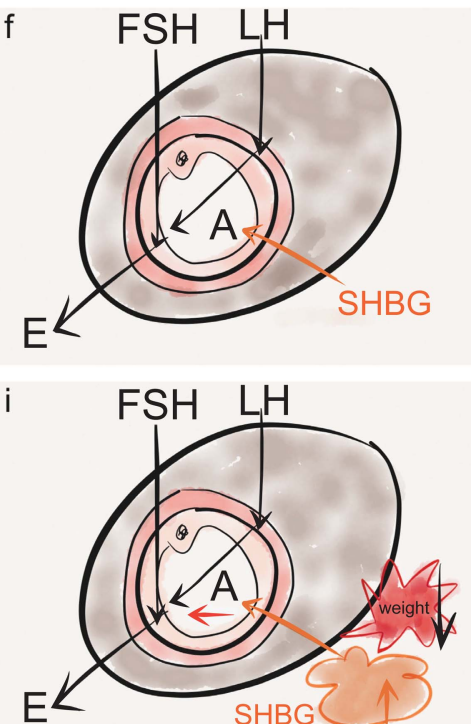

Figure 4 Illustration highlighting the 'sponge' analogy for the role for sex hormone binding globulin (SHBG) in reducing luteinising hormone (LH)-dependent thecal androgen $(\mathrm{A})$ availability, and the link of SHBG to weight and to the increase in free androgen when its level reduces. This does not affect follicle-stimulating hormone (FSH)-stimulated estradiol (E) secretion. See text for an explanation of stages a-i.

\section{Interaction between weight and IR}

The sixth and final stage in understanding the causation of PCOS pulls together the information gained in the first five stages. As LH-induced androgen concentrations can be modified both by weight (through
SHBG change) and by insulin, this can alter the degree by which PCOS is manifested. However the mechanism is not so straightforward, as insulin is an anabolic hormone and the hormone of energy storage. $^{27}$ That means that high levels of insulin are
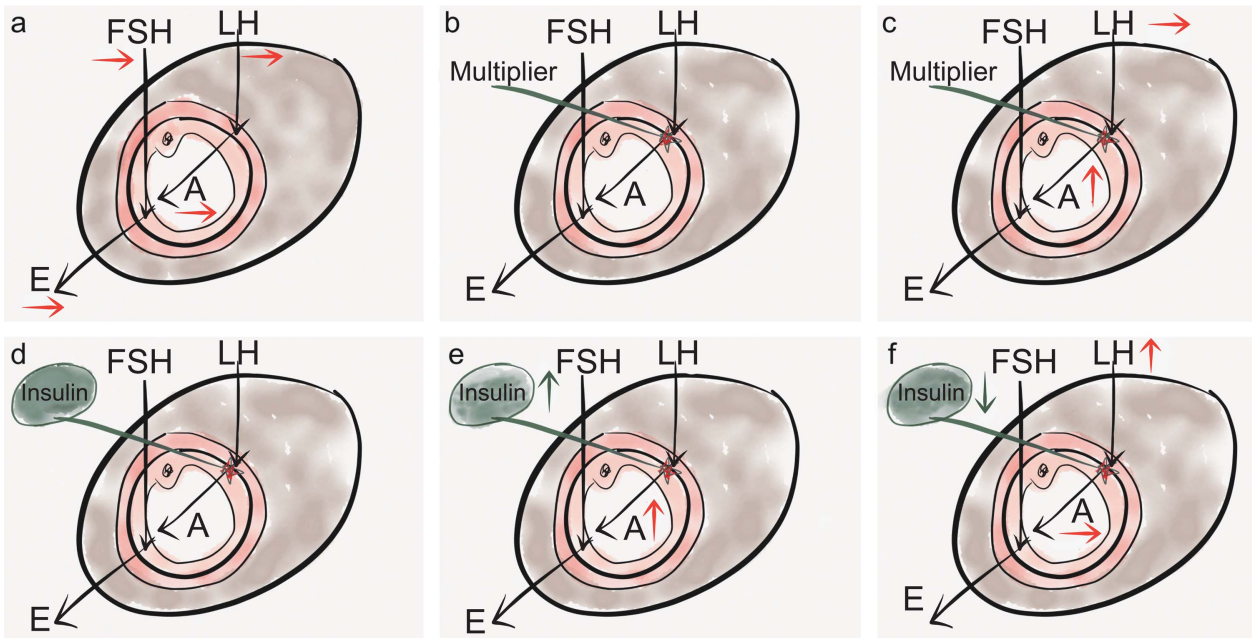

Figure 5 Illustration highlighting the role of insulin in augmenting luteinising hormone (LH)-dependent thecal androgen (A) synthesis, and the reduction in that synthesis if hyperinsulinaemia improves. Follicle-stimulating hormone (FSH)-driven estradiol (E) synthesis continues. See text for an explanation of stages a-f. 
a
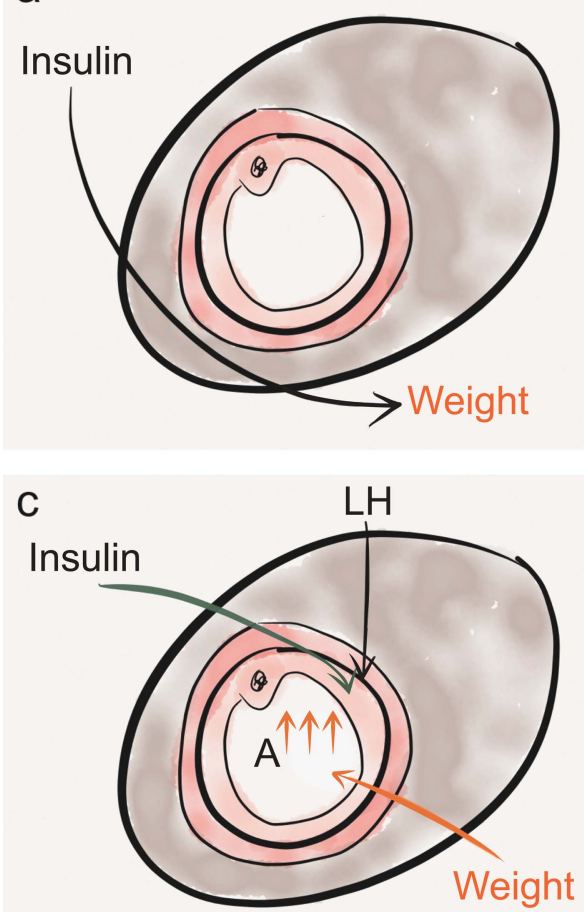

b

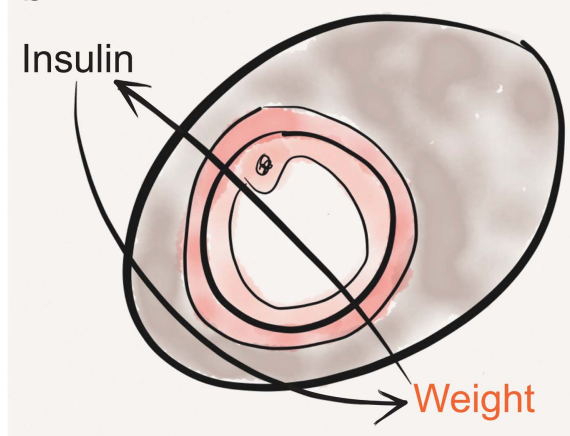

d

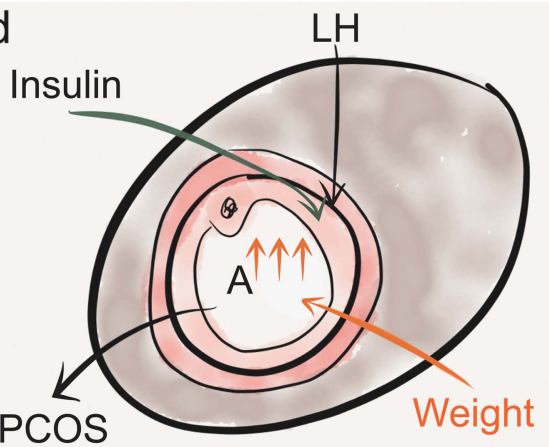

Figure 6 Drawing illustrating the interaction between weight and insulin resistance, leading to augmentation of luteinising hormone (LH)-stimulated androgen (A) secretion, resulting in development of polycystic ovary syndrome (PCOS). See text for an explanation of stages $\mathrm{a}-\mathrm{d}$.

associated with ease of weight gain and difficulty in weight loss (Figure 6a). ${ }^{28}$ As weight increases, IR increases and circulating insulin levels rise, ${ }^{29}$ producing a vicious cycle with weight and IR linked together (Figure 6b). Insulin itself can inhibit hepatic SHBG synthesis. ${ }^{30}$

There are therefore three drivers to increased ovarian androgen production: increased $\mathrm{LH}$, hyperinsulinaemia and increased weight (Figure 6c). So slim women with PCOS have more elevation in LH than obese women with PCOS. ${ }^{31}$ While some women with PCOS primarily have a high LH:FSH ratio, some are primarily insulin resistant and some have a major weight problem. The common consequence is the augmentation of androgens that results in PCOS (Figure 6d). In reality most women with PCOS will have each of these drivers in varying degrees.

\section{A FRAMEWORK FOR THE MANAGEMENT OF PCOS}

The model where LH-stimulated androgen action is augmented by weight and insulin (Figure 6d) provides a useful framework with which to understand PCOS and to explain it to patients and students. But it also provides a useful approach to describe the strategies available for the management of patients with PCOS. The foci could be targeting gonadotrophin concentrations, reducing weight, lowering insulin or ameliorating the systemic effects of ovarian dysfunction and increased androgen levels.

\section{Targeting gonadotrophins}

Any treatment that lowers circulating LH concentrations will reduce ovarian androgen production and improve PCOS (Figure 7a). We do not yet have a treatment to specifically lower $\mathrm{LH}$, so treatment generally involves reducing both $\mathrm{LH}$ and FSH. The main way to do that is with the combined oral contraceptive pill (COC), which is the mainstay of the management of $\mathrm{PCOS}^{32}$ if pregnancy is not desired. Any COC will do this effectively, although it has been argued that the more recent, less androgenic pills may be particularly useful. ${ }^{33}$ As half the androgens in women come from the adrenal gland, ${ }^{34}$ the combination of ethinylestradiol with an anti-androgen such as cyproterone acetate (co-cyprindiol), or a higher dose of cyproterone acetate in a reverse-sequential regimen, ${ }^{35}$ may have additional benefit for certain androgenic symptoms, particularly hirsutism.

For fertility treatment, the strategy is to raise FSH levels to facilitate the conversion of androgens into estrogens in order to remove the brake on follicle growth. As estrogens feed back to inhibit FSH secretion, the use of estrogen antagonists, such as clomifene citrate, or aromatase inhibitors such as letrozole, will raise FSH and improve ovarian function. However estrogen is needed for endometrial growth 

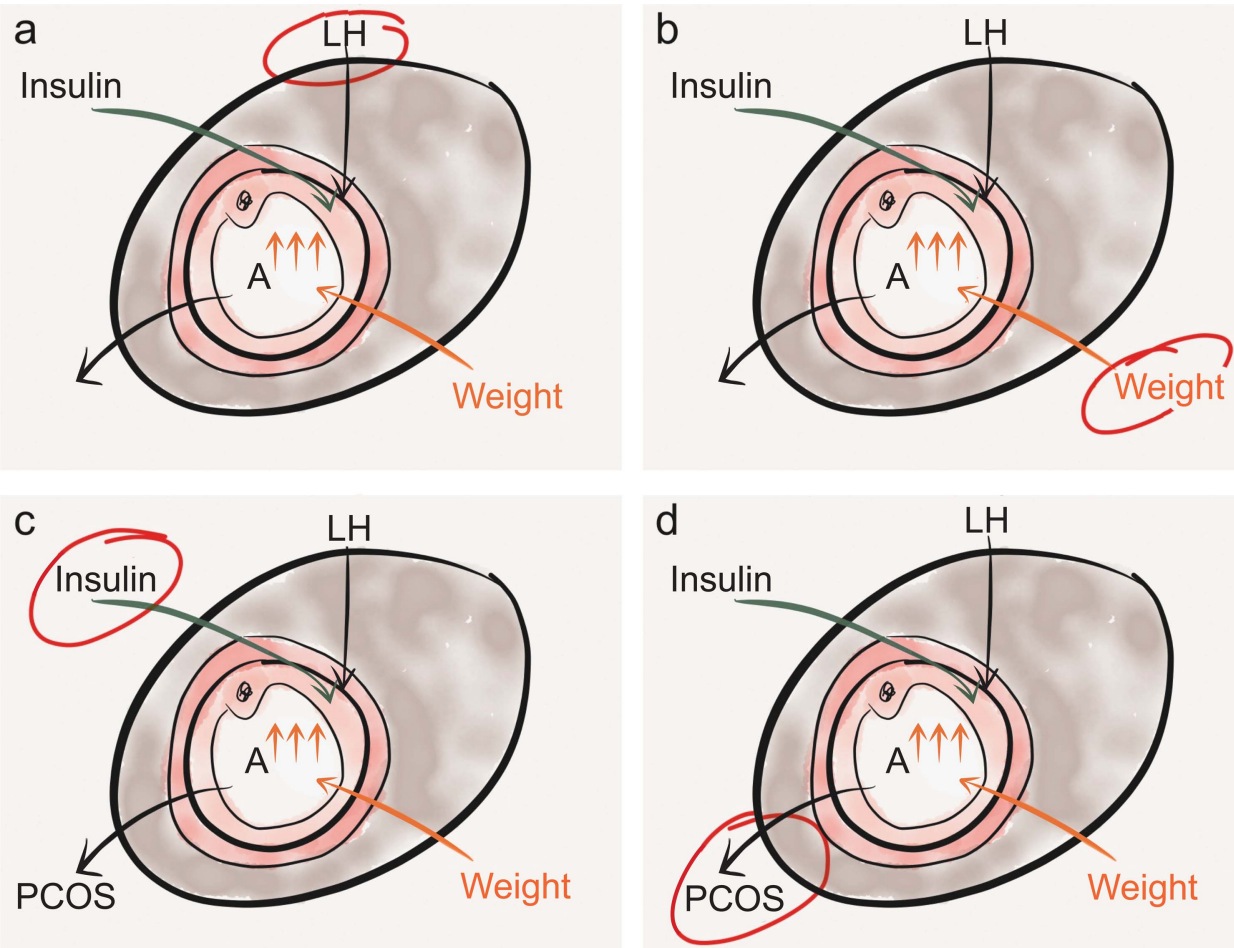

Figure 7 Illustration highlighting the roles of luteinising hormone (LH), increased weight and hyperinsulinaemia in raising intraovarian androgen (A) that results in polycystic ovary syndrome (PCOS). See text for an explanation of stages a-d.

and to stimulate the ovulatory LH surge. Treatment is therefore given only for 5 days at the beginning of the cycle, either from Day 2 or Day 3. If treatment with anti-estrogens at various doses is not effective, then FSH may be directly raised by injections. Gonadotrophin ovulation induction is very successful in the management of subfertility secondary to anovulation in PCOS. ${ }^{36}$

\section{Targeting weight}

Weight loss improves the symptoms PCOS in both non-fertility and fertility contexts (Figure $7 b$ ). In the fertility setting the results are quite dramatic. ${ }^{37} 38$ Thus a weight loss strategy is very important in the management of all overweight and obese women with PCOS. A loss of $10 \%$ of body weight increased fertility, ovulation rate and menstrual regularity even when women remained obese. ${ }^{37}$ In addition there were associated improvements in serum biochemistry, blood pressure and self-esteem scores. ${ }^{37} 38$ It is important to highlight diet, with an emphasis on developing a weight maintenance/weight loss cycle involving regular small healthy meals, not skipping meals and avoiding refined carbohydrate. ${ }^{39}$ However, increased physical activity should always be a key message in weight management. Even in the absence of weight loss, exercise improves PCOS. ${ }^{40}$

\section{Targeting insulin}

Metformin treatment improves insulin sensitivity, thus enhancing glucose clearance, resulting in reduced circulating insulin concentrations (Figure 7c). There is no doubt that metformin can have beneficial effects in some women with PCOS. ${ }^{41} 42$ It can improve feelings of wellbeing, ovarian cyclicity and fertility as a main or as adjunct therapy. ${ }^{43}$ While metformin reduces hyperinsulinaemia $^{44}$ and improves metabolic parameters, its effect on weight loss is more controversial. $^{45}$ The degree of weight loss may relate to how engaged the patient is with a concurrent weight-loss programme. Recent results with metformin have been less impressive than initially reported. ${ }^{46}$ As not all women with PCOS benefit equally from metformin it may be that the key is adequate patient selection. More research is needed into such personalised medicine. However, metformin remains one of the tools available in the management of PCOS. The data on its prolonged use and discontinuation are scanty and variable, so it should not yet be used in the long-term with a goal of preventing future health problems. ${ }^{47-49}$ A current improvement in symptoms associated with PCOS seems a sensible rationale for its continuation.

\section{Holistic targeting}

One of the main areas to focus on is endometrial protection. Women with PCOS who are anovulatory are exposed to unopposed estrogen and are at risk of both prolonged heavy bleeding and the development of endometrial hyperplasia. ${ }^{50}$ It is generally advocated that women with PCOS who are amenorrhoeic should have three or four periods (in the form of withdrawal bleeds) a year to maintain endometrial health. ${ }^{51} \mathrm{~A}$ 
common strategy is to use an intermittent progestogen such as medroxyprogesterone acetate $10 \mathrm{mg}$ twice daily for 7 days or once daily for 10 days. A few days after stopping treatment a withdrawal bleed will occur. If this is particularly heavy it may be that a shorter time between induced periods is required. An alternative approach is to use a COC or the levonorgestrel intrauterine system, both of which will provide full endometrial protection as well as effective contraception, as occasional ovulation could occur despite the amenorrhoea.

Hirsutism is a problem for many women with PCOS. While hormonal treatments such as the COC are designed to reduce ovarian androgens by lowering gonadotrophins, as already mentioned approximately $50 \%$ of androgens in women are of adrenal origin. ${ }^{34}$ Increased androgen promotes the transformation of vellus hair into longer, thicker and more noticeable terminal hair and sometimes reduction of ovarian androgen is insufficient alone to reverse this process. Management of hirsutism may therefore require additional treatments such as cosmetic strategies, local treatment such as topical eflornithine cream or laser therapy (which can be very effective in suitable patients, particularly those with darkly pigmented hair) or systemic treatment with an anti-androgen such as cyproterone acetate 5253 (Figure 7d).

\section{CONCLUSION}

PCOS is a common condition with a varied phenotype. While there might be alternative views on some elements of any framework to understand and manage the syndrome, it is hoped that practitioners involved in teaching students and trainees, and in managing patients, will find that this approach to understanding the condition is helpful.

Author's note This review article is based on a presentation given at a 'Meet the Expert' session at the annual meeting of the British Endocrine Society in 2012.

Competing interests The author is supported by a Scottish Senior Clinical Fellowship from the SFC with grant support from the Medical Research Council (G0901807).

Provenance and peer review Commissioned; externally peer reviewed.

\section{REFERENCES}

1 Polson DW, Adams J, Wadsworth J, et al. Polycystic ovaries - a common finding in normal women. Lancet 1988;1:870-872.

2 Franks S. Polycystic ovary syndrome. N Engl J Med 1995;333:835-861.

3 Motta AB. The role of obesity in the development of polycystic ovary syndrome. Curr Pharm Des 2012;18:2482-2491.

4 The Rotterdam ESHRE/ASRM-sponsored PCOS Consensus Workshop Group. Revised 2003 consensus on diagnostic criteria and longterm health risks related to polycystic ovary syndrome (PCOS). Hum Reprod 2004;19:41-47.

5 Baerwald AR, Adams GP, Pierson RA. Ovarian antral folliculogenesis during the human menstrual cycle: a review. Hum Reprod Update 2012;18:73-91.
6 Minegishi T, Tano M, Igarashi M, et al. Expression of follicle-stimulating hormone receptor in human ovary. Eur J Clin Invest 1997;27:469-474.

7 Tonetta SA, diZerega GS. Intragonadal regulation of follicular maturation. Endocr Rev 1989;10:205-229.

8 Young JM, McNeilly AS. Theca: the forgotten cell of the ovarian follicle. Reproduction 2010;140:489-504.

9 Hillier SG, Whitelaw PF, Smyth CD. Follicular oestrogen synthesis: the 'two-cell, two-gonadotrophin' model revisited. Mol Cell Endocrinol 1994;100:51-54.

10 Child TJ, Abdul-Jalil AK, Gulekli B, et al. In vitro maturation and fertilization of oocytes from unstimulated normal ovaries, polycystic ovaries, and women with polycystic ovary syndrome. Fertil Steril 2001;76:936-942.

11 Balen AH. Ovulation induction in the management of anovulatory polycystic ovary syndrome. Mol Cell Endocrinol 2013;373:77-82.

12 Mathur R, Kailasam C, Jenkins J. Review of the evidence base of strategies to prevent ovarian hyperstimulation syndrome. Hum Fertil 2007;10:75-85.

13 Vendola KA, Zhou J, Adesanya OO, et al. Androgens stimulate early stages of follicular growth in the primate ovary. J Clin Invest 1998;101:2622-2629.

14 Hague WM, Adams J, Rodda C, et al. The prevalence of polycystic ovaries in patients with congenital adrenal hyperplasia and their close relatives. Clin Endocrinol 1990;33:501-510.

15 O'Driscoll JB, Mamtora H, Higginson J, et al. A prospective study of the prevalence of clear-cut endocrine disorders and polycystic ovaries in 350 patients presenting with hirsutism or androgenic alopecia. Clin Endocrinol 1994;41:231-236.

16 Franks S, Adams J, Mason H, et al. Ovulatory disorders in women with polycystic ovary syndrome. Clin Obstet Gynaecol 1985;12:605-632.

17 García-Rudaz MC, Ropelato MG, Escobar ME, et al. Augmented frequency and mass of LH discharged per burst are accompanied by marked disorderliness of LH secretion in adolescents with polycystic ovary syndrome. Eur J Endocrinol 1998;139:621-630.

18 McCartney CR, Eagleson CA, Marshall JC. Regulation of gonadotropin secretion: implications for polycystic ovary syndrome. Semin Reprod Med 2002;20:317-326.

19 Abbott DH, Nicol LE, Levine JE, et al. Nonhuman primate models of polycystic ovary syndrome. Mol Cell Endocrinol 2013;373:21-28.

20 Padmanabhan V, Veiga-Lopez A. Sheep models of polycystic ovary syndrome phenotype. Mol Cell Endocrinol 2013;373:8-20.

21 Eisner JR, Barnett MA, Dumesic DA, et al. Ovarian hyperandrogenism in adult female rhesus monkeys exposed to prenatal androgen excess. Fertil Steril 2002;77:167-172.

22 Abbott DH, Barnett DK, Bruns CM, et al. Androgen excess fetal programming of female reproduction: a developmental aetiology for polycystic ovary syndrome? Hum Reprod Update 2005;11:357-374.

23 Longcope C, Feldman HA, McKinlay JB, et al. Diet and sex hormone-binding globulin. J Clin Endocrinol Metab 2000;85:293-296.

24 Dunaif A. Insulin resistance and the polycystic ovary syndrome: mechanism and implications for pathogenesis. Endocr Rev 1997;18:774-800.

25 Zhang G, Garmey JC, Veldhuis JD. Interactive stimulation by luteinizing hormone and insulin of the steroidogenic acute 
regulatory (StAR) protein and 17alpha-hydroxylase/17,20-lyase (CYP17) genes in porcine theca cells. Endocrinology 2000;141:2735-2742.

26 Nahum R, Thong KJ, Hillier SG. Metabolic regulation of androgen production by human thecal cells in vitro. Hum Reprod 1995;10:75-81.

27 Dimitriadis G, Mitrou P, Lambadiari V, et al. Insulin effects in muscle and adipose tissue. Diabetes Res Clin Pract 2011;93: S52-S59.

28 Flatt PR, Tan KS, Swanston-Flatt SK, et al. Metabolic effects and secretory properties of a radiation-induced transplantable rat insulinoma. Comp Biochem Physiol A Comp Physiol 1987;87:175-181.

29 Heilbronn LK, Coster AC, Campbell LV, et al. The effect of short term overfeeding on serum lipids in healthy humans. Obesity 2013;21:E649-E659.

30 Pugeat M, Nader N, Hogeveen K, et al. Sex hormone-binding globulin gene expression in the liver: drugs and the metabolic syndrome. Mol Cell Endocrinol 2010;316:53-59.

31 Pagán YL, Srouji SS, Jimenez Y, et al. Inverse relationship between luteinizing hormone and body mass index in polycystic ovarian syndrome: investigation of hypothalamic and pituitary contributions. J Clin Endocrinol Metab 2006;91:1309-1316.

32 Setji TL, Brown AJ. Comprehensive clinical management of polycystic ovary syndrome. Minerva Med 2007;98:175-189.

33 Kriplani A, Periyasamy AJ, Agarwal N, et al. Effect of oral contraceptive containing ethinyl estradiol combined with drospirenone vs. desogestrel on clinical and biochemical parameters in patients with polycystic ovary syndrome. Contraception 2010;82:139-146.

34 Labrie F, Luu-The V, Labrie C, et al. Endocrine and intracrine sources of androgens in women: inhibition of breast cancer and other roles of androgens and their precursor dehydroepiandrosterone. Endocr Rev 2003;24:152-182.

35 Carmina E, Lobo RA. A comparison of the relative efficacy of antiandrogens for the treatment of acne in hyperandrogenic women. Clin Endocrinol 2002;57:231-234.

36 Li HW, Van Esch M, De Vries J, et al. Gonadotrophin ovulation induction is a successful treatment for World Health Organisation Group II anovulatory subfertility in women aged up to 40 and with body mass index up to 34 . Hum Fertil (Camb) 2010;13:35-40.

37 Clark AM, Ledger W, Galletly C, et al. Weight loss results in significant improvement in pregnancy and ovulation rates in anovulatory obese women. Hum Reprod 1995;10:2705-2712.

38 Norman RJ, Noakes M, Wu R, et al. Improving reproductive performance in overweight/obese women with effective weight management. Hum Reprod Update 2004;10:267-280.
39 Moran LJ, Ko H, Misso M, et al. Dietary composition in the treatment of polycystic ovary syndrome: a systematic review to inform evidence-based guidelines. I Acad Nutr Diet 2013;113:520-545.

40 Harrison CL, Lombard CB, Moran LJ, et al. Exercise therapy in polycystic ovary syndrome: a systematic review. Hum Reprod Update 2011;17:171-183.

41 Palomba S, Falbo A, Zullo F Jr, et al. Evidence-based and potential benefits of metformin in the polycystic ovary syndrome: a comprehensive review. Endocr Rev 2009;30:1-50.

42 Moll E, van der Veen F, van Wely M. The role of metformin in polycystic ovary syndrome: a systematic review. Hum Reprod Update 2007;13:527-537.

43 Xiao J, Chen S, Zhang C, et al. The effectiveness of metformin ovulation induction treatment in patients with PCOS: a systematic review and meta-analysis. Gynecol Endocrinol 2013;28:956-960.

44 Dunaif A. Drug insight: insulin-sensitizing drugs in the treatment of polycystic ovary syndrome - a reappraisal. Nature Clin Pract Endocrinol Metab 2008;4:272-283.

45 Nieuwenhuis-Ruifrok AE, Kuchenbecker WK, Hoek A, et al. Insulin sensitizing drugs for weight loss in women of reproductive age who are overweight or obese: systematic review and meta-analysis. Hum Reprod Update 2009; 15:57-68.

46 Tang T, Balen AH. Use of metformin for women with polycystic ovary syndrome. Hum Reprod Update 2013; 19:1.

47 Lord JM, Flight IHK, Norman RJ. Metformin in polycystic ovary syndrome: systematic review and meta-analysis. BMJ 2003;327:951-953.

48 Palomba S, Falbo A, Russo T Jr, et al. Insulin sensitivity after metformin suspension in normal-weight women with polycystic ovary syndrome. J Clin Endocrinol Metab 2007;92:3128-3135.

49 Cheang KI, Huszar JM, Best AM, et al. Long-term effect of metformin on metabolic parameters in the polycystic ovary syndrome. Diab Vasc Dis Res 2009;6:110-119.

50 Giudice LC. Endometrium in PCOS: implantation and predisposition to endocrine CA. Best Pract Res Clin Endocrinol Metab 2006;20:235-244.

51 Fauser BC, Tarlatzis BC, Rebar RW, et al. Consensus on women's health aspects of polycystic ovary syndrome (PCOS): the Amsterdam ESHRE/ASRM-Sponsored 3rd PCOS Consensus Workshop Group. Fertil Steril 2012;97:28-38.

52 Conn JJ, Jacobs HS. Managing hirsutism in gynaecological practice. Br J Obstet Gynaecol 1998;105:687-696.

53 Franks S. The investigation and management of hirsutism. J Fam Plann Reprod Health Care 2012;38:182-186.

\section{READERS' CONTRIBUTIONS INVITED ON 'A BETTER WAY OF WORKING'}

The Journal publishes occasional 'A Better Way of Working' articles, the purpose of which is to disseminate service delivery suggestions likely to be of interest and relevance to the Journal's readership. Readers are invited to submit suggestions based on their own personal experience for consideration by the Journal Editor. Contributions normally should not exceed 1000 words and should be written in a standardised format responding to the following four questions (or similar): Why was change needed? How did you go about implementing change? What advice would you give to others who might be considering a similar course of action? How did you show that the change had occurred? All contributions should be submitted via the Journal's online submission system at http://mc.manuscriptcentral.com/jfprhc. 